\title{
UNA NUEVA OBRA DEL MAESTRO DE AÑASTRO: LA TABLA DE MEDRANO (MUSEO DIOCESANO DE CALAHORRA)
}

En el Museo Diocesano de Calahorra se conserva una tabla representando a un santo obispo, sin identificar, que procede de la población riojana de Medrano ${ }^{1}$. La tabla posee reducidas dimensiones, $96,5 \times 35 \mathrm{~cm}$. Al presentar pinturas también por el reverso nos lleva a pensar que era una de las alas de un tríptico o políptico.

En el anverso el santo obispo aparece ataviado con las vestiduras litúrgicas propias de su cargo: mitra, alba, dalmática ${ }^{2}$, sobre ésta, casulla. Sostiene en su mano derecha un báculo propio también de su condición. En la mano izquierda, sobre la muñeca, lleva un manípulo, y con la mano sostiene un libro cerrado. Es de destacar el detalle de los cuellos, que imitan rico bordado. Se trata de una pintura colorista, los tonos son sencillos pero vivos, sin sombras ni gradaciones. La túnica es blanca, la dalmática es azulada, lo mismo que su amplio nimbo, y la casulla, como contraste de color, es roja, al igual que los adornos de su mitra blanca. El fondo neutro sobre el que se ha dispuesto, en la actualidad presenta un tono amarillento que nos lleva a preguntarnos si en su día fue dorado o bien siempre ha sido una pintura amarilla imitando oro. El pintor dispuso al santo sobre un suelo de rocas redondeadas y sombreadas con cortas líneas verticales paralelas, sobre las que volveremos más adelante.

En el reverso de la tabla encontramos sólo pequeños fragmentos de escenas difíciles de identificar ocultas por una pintura rojiza posterior. En la parte superior, a nuestra izquierda, se aprecia el fragmento de mayor tamaño. Bajo una arquería, que parece se compuso de tres arcos, el central mayor que los laterales, contenidos en otra estructura más amplia (¿gablete?), se encuentran dos figuras. La de nuestra izquierda corresponde, por su tocado, a la de un monarca. Por la altura que presenta lleva a pensar que se hallaba sentado. Ante él, y a nuestra derecha aparece la figura nimbada de un obispo, sin duda el representado en el anverso. Su actitud es la de diálogo. Esta parte muestra un menor detallismo y una ejecución más descuidada, pero parece corresponder al mismo maestro.

En la parte inferior del reverso, a nuestra izquierda también, hallamos una tercera figura que muestra a un joven ataviado con la moda correspondiente a la época de realización de la pintura. Cubre su cabeza con tocado rojo, parecido al del monarca de la parte superior, pero sin la corona, y una jaqueta de tono crema adornada por un cinturón a la altura de la cadera, mientras que sus pantalones son rojos. Es de destacar la inestabilidad de su posición, o lo forzado de la misma, con el cuerpo de frente al espectador, la cabeza girada mirando hacia abajo y las piernas abiertas. Una de sus manos, la izquierda, la tiene sobre su cadera mientras que el brazo derecho parece tenerlo elevado. También es interesante comprobar que parece que faltan sus pupilas, como si hubiesen sido eliminadas a propósito. Esto puede llevarnos a pensar en que la tabla sufrió una agresión en un momento determinado sin saber las causas, pero

\footnotetext{
${ }^{1}$ Esta pintura aparece mencionada en Moya Valgañón, J. G., (Dir.), Inventario del Patrimonio Artístico de España. Logroño y su Provincia. Madrid, 1976, t. II, p. 356, lám. 197. En aquel momento se encontraba en el trastero de la parroquia de Medrano, junto con otras piezas, que se trasladaron también al Museo de Calahorra en 1973. Se identificó en el reverso una Epifanía oculta por repintes. Se le considera una obra de la primera mitad del S. XIV. También a ella se refiere A.M. Galilea Antón en Aportación al Estudio de la Pintura Gótica sobre Tabla y Sarga en La Rioja, Logroño, 1985, p. 17 y 18. Es hasta el momento el estudio más amplio que se ha realizado sobre esta pintura. La autora identifica al santo obispo como San Blas. Considera que la pintura debe fecharse entre 1300 y 1330.

${ }^{2}$ Aunque la dalmática es una prenda que se asocia tradicionalmente con el diácono, el obispo en las misas pontificales bajo la casulla viste, en memoria del uso primitivo, dalmática y túnica (o tunicella). Sobre este particular véase, Cabrol, F., La Oración de la Iglesia. Barcelona, 1909, p. 436; Gudiol I Cunill, J., L'Indumentaria Litúrgica. Vich, 1918, pp. 19 y 27; Aldazabal, J., Vocabulario Básico de Liturgia, Barcelona, 1996 (2a ed.), p. 117.
} 
también, y no es extraño, en un acto de devoción, lo que implicaría un sentido negativo de esta figura masculina, quizás un sayón. El fondo neutro del reverso también presenta ese tono amarillento.

Iconográficamente no es fácil identificar al santo obispo, pues aparte del báculo y el libro no lleva ningún elemento especial que pueda ayfídarnos. Por otra parte, las escenas del reverso, que consideramos son referentes al santo pues aparece con indumentaria similar, por su fragmentación y lo común entre las vidas de santos -santo obispo ante un monarca- no ayudan a la identificación. Posiblemente debamos ponerlo en relación con algún santo de especial devoción en Medrano o zona cercana. En el campo de la hipótesis, Galilea Antón ${ }^{3}$ lo identifica con San Blas, de devoción muy extendida y que sufrió martirio. Pero en todo caso, mientras no podamos averiguar más sobre las escenas que contiene el reverso de la tabla, difícilmente nos podremos acercar a su contenido iconográfico.

En cuanto al estilo que presenta la tabla, con la línea como elemento fundamental que no sólo delimita el contorno de las figuras sino que también dibuja plegados y rasgos faciales, sin perspectiva, con figuras sobre fondos neutros, con colores vivos, sin volumen ni sombreados, con escenas cobijadas bajo arquería, corresponde a la corriente del Gótico Lineal.

Por otra parte y ciñéndonos de forma exclusiva al estilo del artista que realizó la pintura, observamos que tiene unos rasgos muy definidos que corresponden posiblemente a una personalidad artística ya madura. Las líneas de los cuerpos tienden a ser largas y realizadas con precisión. Por otra parte aparece claro el dominio del autor de las líneas más curvas para ofrecer un intento de volumen y corporeidad en los ropajes, por ejemplo, en la casulla del santo obispo del anverso. Es un creador detallista, dentro de lo que corresponde a una pintura de este estilo lejana a los focos creadores más destacados. Así lo apreciamos en la decoración de la mitra, pero también en cómo delinea los mechones del cabello en las figuras, más perfectos en la del anverso. Ese detallismo también puede apreciarse en la decoración de las tapas del libro que lleva el obispo. Sus figuras tienden a cierta estilización, visible también en las manos, en especial en los dedos largos y estrechos.

Los rostros son también muy particulares, y no sólo por la disposición de los mechones de cabello que los enmarcan. Tienden a aparecer en posición tres cuartos y son redondeados, a excepción de la barbilla que se muestra marcada por otra línea. Los ojos son un tanto rasgados, con la pupila en el extremo ancho. La nariz se realiza con dos trazos, uno largo que dibuja también una de las cejas y otro corto de unión al rostro. Los labios, pequeños, se componen de tres pequeños trazos curvos que se repiten en los cuatro rostros de la tabla.

Todas estas características tan propias del maestro que ejecutó la tabla de Medrano son las mismas que encontramos en el retablo de San Andrés de Añastro (Condado de Treviño) ${ }^{4}$ y en la tabla del Martirio de Santa Catalina (A. I. Chicago), cuyo origen se desconoce, ya que, retrocediendo en el tiempo, la única noticia que tenemos es que fue vendida en una subasta de obras de arte en París.

\footnotetext{
${ }^{3}$ Galilea Antón, A. M., Idem, p. 17.

${ }^{4}$ El retablo de San Andrés se encuentra disperso. La tabla central, que representaba a San Andrés sedente flanqueado por ángeles y Apóstoles, se halla en la Excma. Diputación de Burgos, una de las tablas laterales se encuentra en el Museo Zuloaga de Zumaya (Guipúzcoa), mientras que la otra está en el Museo The Cloisters, de Nueva York (Estados Unidos). Desconocemos las fechas en que salieron ambas tablas laterales de Añastro, pero sin duda en fechas ya antiguas, quizás finales del siglo XIX o principios del XX.
} 
El retablo de Añastro', con pinturas en el reverso, también corresponde a los retablos cerraderos que parecen ser muy típicos de la zona, ya que recordemos que el retablo gótico de San Millán de la Cogolla también era cerradero, por no citar el elevado número de ellos en la cercana Álava. Sobre la tabla de Santa Catalina en ninguna publicación se menciona que posea pintura en su reverso ${ }^{6}$.

Físicamente la figura del anverso de Medrano, recuerda en gran medida a los ángeles de la tabla central de Añastro, en especial a esos cabellos tan trabajados que presentan. Es este aspecto el que más recuerda a las figuras de otro destacado retablo de cronología similar, el encargado por D. Pero López de Ayala para su capilla funeraria de Quejana, 13967. Como ocurre en Quejana, en Medrano, el cabello del santo obispo se ha dispuesto en mechones de tonos amarillos y un tono más oscuro, alternảdos, que crea una rudimentaria imagen de volumen.

Otro detalle de la tabla de Medrano que hace indiscutible su atribución al Maestro de Añastro es la forma de realizar las piedras del suelo, redondas y con trazos verticales, como se aprecia en cualquier escena al aire libre de este Maestro, tanto en la tabla de Santa Catalina como en el retablo de Añastro, donde, en las escenas del Génesis, por ejemplo, en la de la Creación, además de esas líneas verticales el autor dispuso pequeños tréboles apenas visibles, y que, desde luego no están en Medrano. En cambio, el autor de Quejana, aunque mostraba el suelo de forma parecida, lo hacía por medio de piedras de formas más rectas, como si se tratase de adoquines más que de terreno pedregoso.

En el aspecto del tratamiento de la indumentaria, observamos que también hay puntos comunes entre la tabla de Medrano y las otras dos obras del Maestro. Así, muy especialmente si lo comparamos con la tabla de Santa Catalina o el reverso de Añastro, observamos esos pliegues dibujados con precisión, algunos de ellos largos y rectos con un trazo negro, y otros angulosos para dar una idea de plegado en «V» que intentan alcanzar cierta corporeidad. También hallamos igual el detalle de los ropajes cayendo sobre el suelo, casi ocultando los pies de las figuras y quedando recogidos ligeramente sobre las rocas.

Por lo tanto, la tabla de Medrano tiene una importancia no sólo por sí misma, al ser escasas las obras del Gótico Lineal conservadas en La Rioja, sino también en el estudio de una figura como es el Maestro de Añastro. Nos ayuda y nos plantea nuevōs interrogantes acerca de esta personalidad tan poco conocida y de su trayectoria artística.

\footnotetext{
${ }^{5}$ Sobre el retablo de San Andrés de Añastro, se puede consultar entre otros, Post, Ch. R., A History of Spanish Painting, II, pp. 133-136; Wheler, H. B., The Metropolitan Museum of Art. A Catalogue of Italian, Spanish and Byzantine Paintings, New York 1940, pp. 211-212; Cook, W., y Gudiol Ricart, J., Pintura Románica, Imaginería Románica, Ars Hispaniae, VI, Madrid 150, p. 261 y Madrid 1980, pp. 238-239; Gaya Nuño, J. A., La Pintura Española fuera de España, Madrid 1958, p. 89; Portilla, M. J., y Eguia, J., Arciprestazgos de Treviño, Albaina y Campezo, Catálogo Monumental de la Diócesis de Vitoria, tomo II, Vitoria 1968, pp. 53-54; Sáenz Pascual, R., «Un ejemplo de Gótico Lineal tardío: el Retablo de San Andrés de Añastro, en Cuadernos de Sección. Artes Plásticas y Monumentales, 15, (1996), pp. 471 y 481, y en La Pintura Gótica en Alava. Una Contribución a su Estudio, Vitoria, 1997, pp. 137-179.

${ }^{6}$ Referencias a esta tabla se pueden encontrar en el Bulletin of the Art Institute of Chicago, XXVIII, 2, (1934), p. 20; Catalogue of a Century of Progress. Exhibition of Painting and Sculpture, Chicago 1943, . 3; The Art Digest, (mayo, 1934), p. 29; Sáenz Pascual, R. Idem, 1997, pp. 172-174.

${ }^{7}$ Son numerosas las publicaciones que se refieren a este retablo, entre ellas podemos destacar las siguientes: Becerro de Bengoa «De Miranda a Ayala y Llodio», en Descripciones de Álava, 1880, en Ateneo, 61, (1918), p. 6; Tormo, E., «El retaule de Quejana», en Vell i Nou, 47, (1917), p. 476; Post, Ch. R., A History of Spanish Painting, Vol. II. Cambridge, Mass, 1930, pp. 126-133; Camon Aznar, J., Pintura Medieval Española, Summa Artis, XXII, Madrid 1966, pp. 171-173; Maxon, J., «The Ayala altarpiece», en The Art Institute of Chicago, Nueva York 1970, pp. 24-25; Silva y Verastegui, S. de, «Las empresas artísticas del Canciller Pero López de Ayala», en Vitoria en la Edad Media, Vitoria 1982, pp. 761-778; Portilla, M. J., Vertientes Cantábricas del Noroeste Alavés. La Ciudad de Orduña y sus Aldeas, Catálogo Monumental de la Diócesis de Vitoria, tomo VI, Vitoria, 1988, pp. 787-792, Sáenz Pascual, R, Idem, 1997, pp. 87-136.
} 

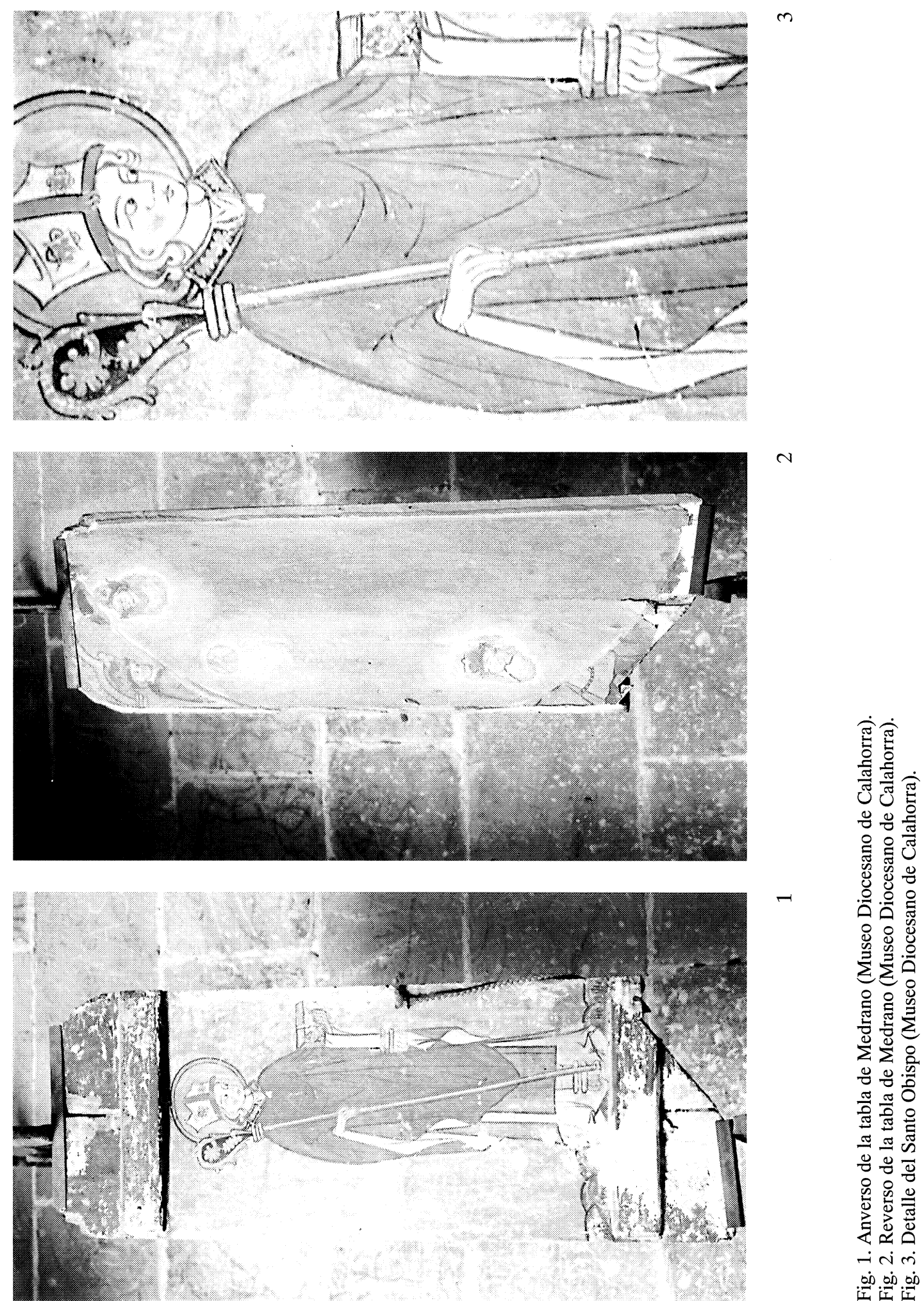


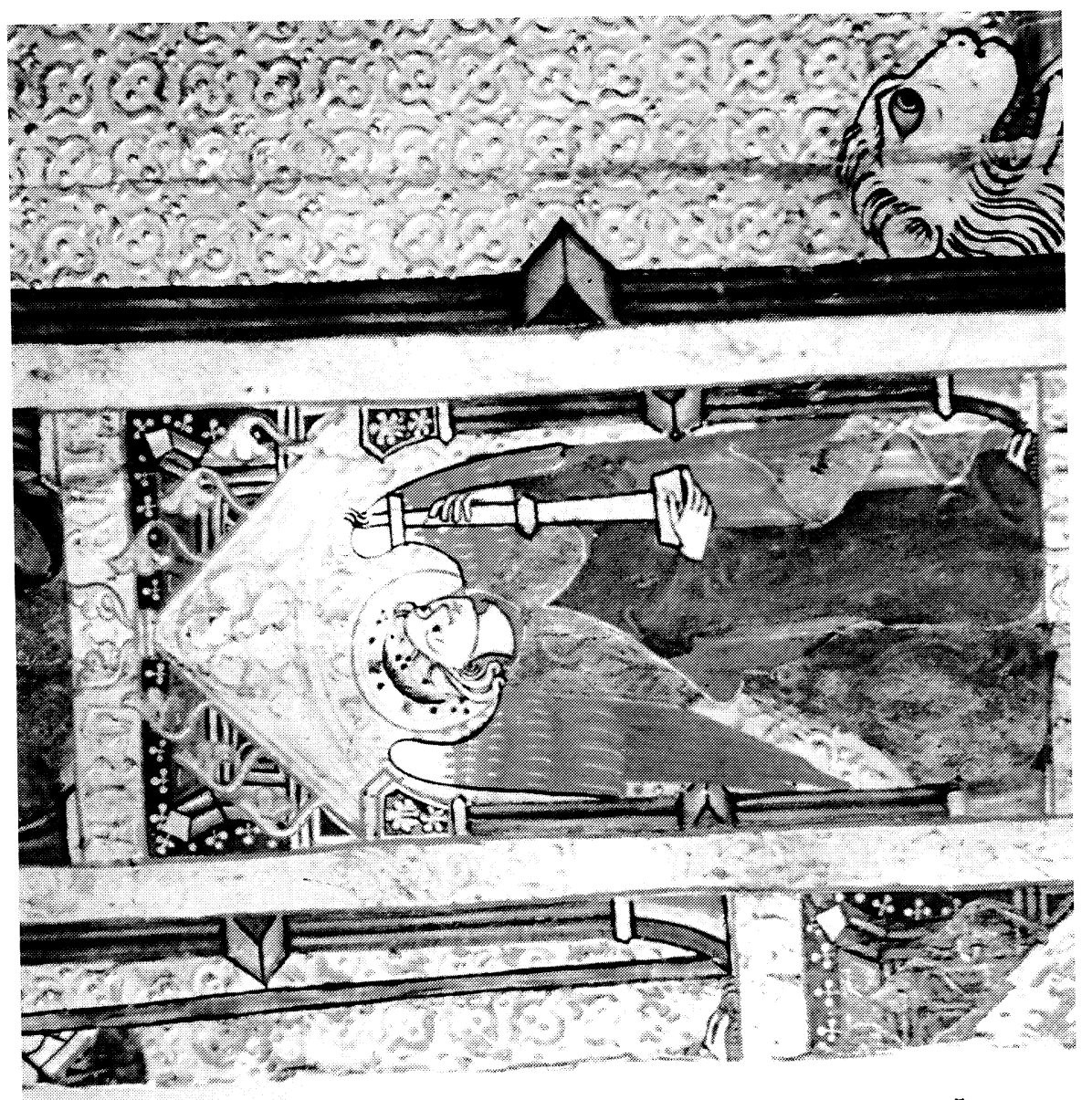

n

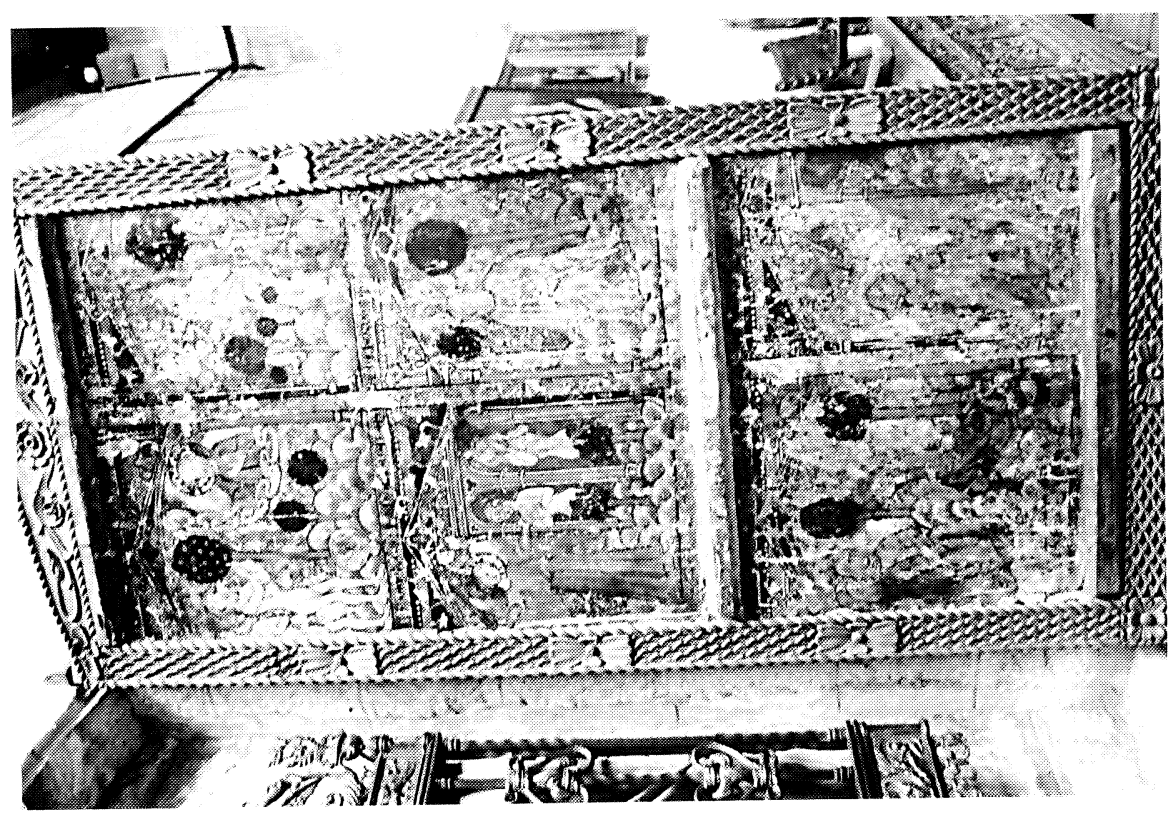


Podríamos fechar esta tabla de Medrano en los años finales del S. XIV, lo que se aprecia bien en la indumentaria de las figuras, como esa jaqueta con cinturón en la cadera y la corona embutida en el sombrero. Esa es la cronología de las tres obras con las que estamos comparando básicamente esta pintura. Creemos que estilísticamente no tiene relación con la otra gran obra riojana del Gótico, el retablo de San Millán de la Cogolla, con influencia italiana y que se fecha en el S. XIV pero no antes de $1340^{8}$. En resumen, el Maestro de Añastro, a través de la tabla de Medrano, muestra una continuidad en sus características. Es muy importante puesto que vemos que es un artista que trabaja en un territorio ya de cierta extensión, aunque no se trate de distancias enormes, Condado de Treviño y La Rioja. Recordemos que por entonces Treviño se relacionaba de forma estrecha con Vitoria, pues eran villas colindantes. Medrano pertenece a otra zona de influencia diferente. En cuanto a la tabla de Santa Catalina era imposible determinar su origen, aparte de saber que es del norte de España. Por ello, conocer algo más de la zona de trabajo de este Maestro de Añastro y su movilidad es algo muy satisfactorio.

Por otra parte, el hecho de que aún queden pinturas sin estudiar nos lleva a tener la esperanza de que en un futuro se pueda profundizar en el conocimiento de este Maestro y que puedan aparecer nuevas obras suyas. En todo caso, hoy por hoy, son ya tres las obras conocidas de su mano: el retablo de San Andrés de Añastro, la tabla del Martirio de Santa Catalina y la tabla del Santo Obispo de Medrano (La Rioja).

Raquel SÁEnz Pascual

Dra. por la UPV / Becaria adscrita al Dpto. $\mathrm{H}^{\mathrm{a}}$ Arte del CSIC

${ }^{8}$ Sobre las tablas de San Millán de la Cogolla, se puede consultar la obra de Galilea Antón, A., Idem, 1985, pp. 19-32, esp. pp. 31 y 32 . 